MATEC Web of Conferences 22,03004 (2015)

DOI: $10.1051 /$ matec conf/ 20152203004

(C) Owned by the authors, published by EDP Sciences, 2015

\title{
Simulation on Dual-stream Transmission System of Unmanned Tracked Armored Vehicle Using ADAMS
}

\author{
Wei Sun, Yao Zhao, Weiqiang Zheng \& Bing Ma \\ Academy of Armored Forces Engineering, Beijing, China
}

\begin{abstract}
For the dual-stream transmission system of unmanned tracked armored vehicle, simulation analysis is carried out. Using SolidWorks to establish three-dimensional model of its chassis, the result of the simulation is processed in AdAMS/Solver. The simulation results are showed in lines. Comparative analysis for each simulation lines is conducted, and it verifies the feasibility of the dual-stream transmission system.
\end{abstract}

Keywords: dual-stream transmission; simulation analysis; ADAMS

\section{INTRODUCTION}

With the development of modern war from mechanization to informatization, unmanned mobile platform has been a great development in the field of wheeled vehicles, but few studies have been conducted in tracked armored field which applies to combat and logistics support. Unmanned tracked armored vehicle has important role in beach landings, fire assault and other large casualties' circumstances. A research on unmanned tracked armored vehicle has been developed based on a retired armored personnel carrier. It used the maximum effectiveness of the retired equipment. In order to realize the stepless steering in unmanned tracked armored vehicle, the conventional method is to use the dual-stream transmission technology. This paper is aiming at the simulation analysis of the dual-stream transmission in unmanned tracked vehicle on Adams.

Unmanned tracked vehicle belongs to the high speed military tracked vehicle, and its steering is different from wheeled vehicle. In various embodiments, the performance of zero differential dual-stream transmission is best. It can realize stepless steering. So the zero differential dual-stream transmission is selected.
The zero differential dual-stream transmission is a closed speed control system composed of variable plunger pumps and quantitative plunger motors, and it can realize stepless bidirectional speed control. Motor torque can maintain constant power variation in regulating of the motor speed (Sun 2006). So this system has the peculiarity of constant torque output. The system integrates flush valve, supply pump, and so on Figure 1 is the mechanism design sketch of unmanned tracked vehicle steering system.

\section{MODELING AND ASSEMBLY}

Modeling of dual-stream steering mechanism is mainly divided into two parts: one is modeling and assembly of the planetary gear; the other one is assembly of zero axis and other transmission parts. Use plug-in unit Toolbox of SolidWorks, model of all the gear parts and save files in accordance with their name. Then the planet carrier, the shaft parts, the box body and the hydraulic motor are modeled in accordance with the calculated dimensions. These models need to be calculated and set aside the installation size, in order to ensure the assembly work smoothly. Some modeling results are shown in Figure 2.

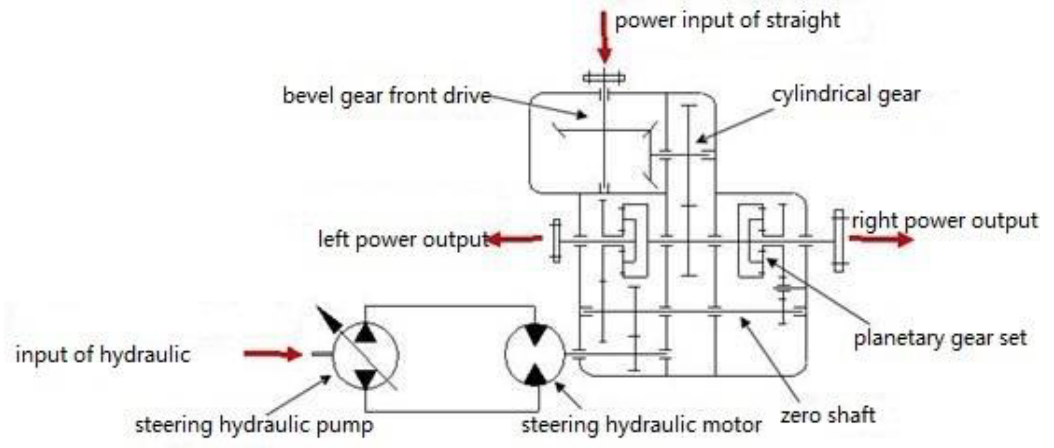

Figure 1. Mechanism design sketch of unmanned tracked vehicle steering system.

This is an Open Access article distributed under the terms of the Creative Commons Attribution License 4.0, which permits unrestricted use, distribution, and reproduction in any medium, provided the original work is properly cited. 


\section{MATEC Web of Conferences}
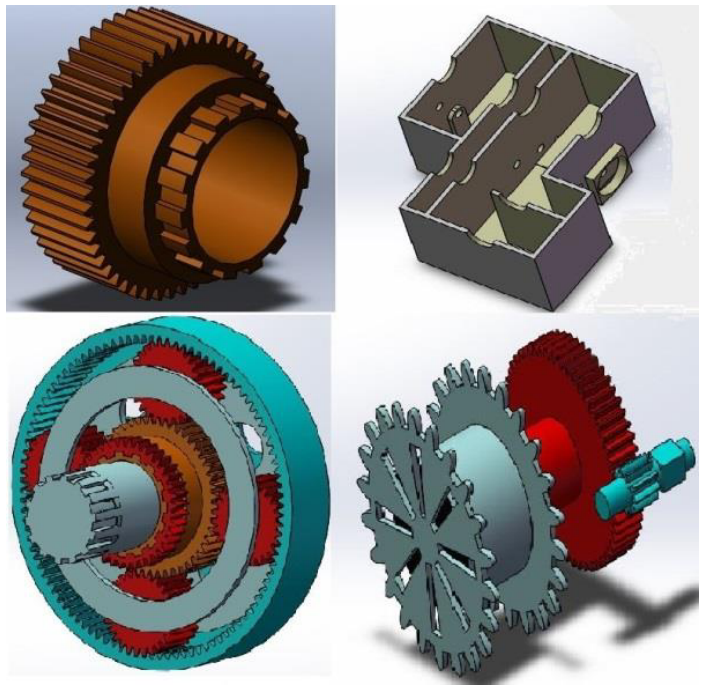

Figure 2. Part model.

Simulation is mainly carried out for the dual-stream transmission. So the modeling of engine makes a simplified shape model according to the shape parameters, with long straight axis taking the place of crankshaft. Because the both ends of engine output power, the crankshaft needs to be extended at the both ends and reserved connection head. According to the overall plan layout, assemble all parts of set. The results are shown in Figure 3.

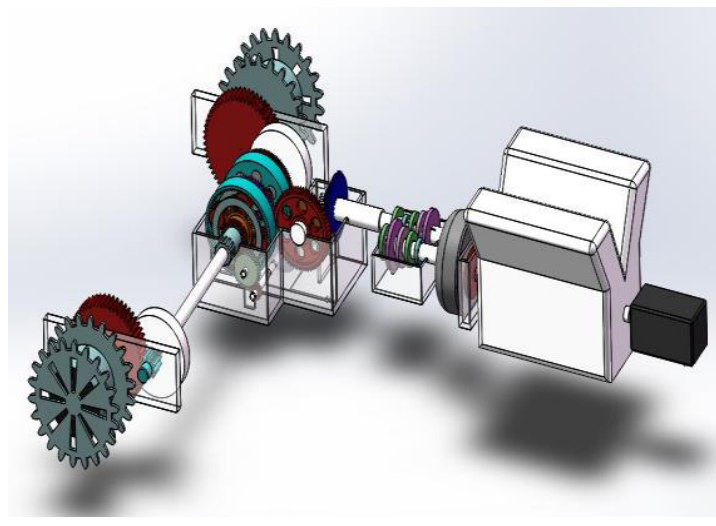

Figure 3. General assembly drawing.

\section{SIMULATION OF DUAL-STREAM TRANS} MISSION

The model established by software SolidWorks imports into Adams through the format of X T. Retaining the relative position between the components, add constraints and simulative power. Run in the simulation environment and output results in the form of chart. The constraints mainly comprise locking, revolute joints and gear pairs. In the constraints of dual-stream steering mechanism, in order to simplify the model, we should put gear mesh in gear pairs as constraint condition except the three components of planetary units.

\subsection{The constant radius steering Simulation}

Introduce parameter: relative rate of change of hydraulic pump. It represents the ratio of a moment of displacement in hydraulic pump to the maximum displacement:

$$
\varepsilon=\frac{q_{b}}{q_{b \max }}
$$

The range of $\mathcal{E}$ is $-1 \leq \mathcal{E} \leq 1$. The simulation condition is described in Table 1:

Some simulation results are shown in Figures 4-8:

In every gear, the speed of two sides in the planet carrier has a clear distinction. The lines are overall straight and parallel. This indicates that vehicle can keep relatively stable steering radius. According to the calculation formula of relative steering radius:

$$
\rho=\left(v_{1}+v_{2}\right) /\left[0.5 \times\left(v_{1}-v_{2}\right)\right]
$$

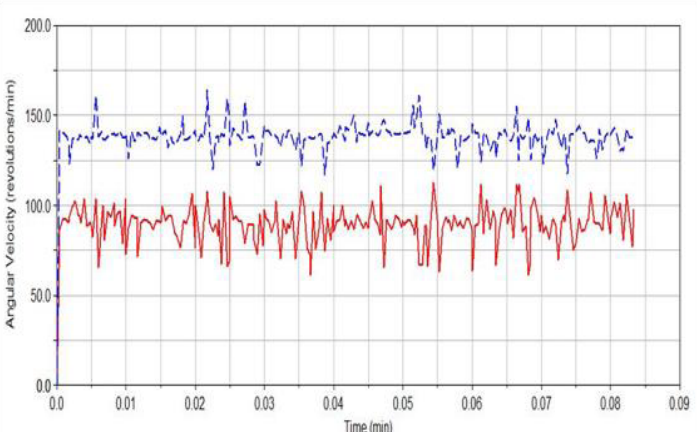

Figure 4. Speed of planet carrier in constant radius steering of gear 1.

Table 1. Simulation of constant radius steering

\begin{tabular}{llllllll}
\hline No. & The simulation condition & $\begin{array}{l}\text { The engine speed } \\
\mathrm{r} / \mathrm{min}\end{array}$ & $\mathrm{Gear}$ & $i_{b}$ & $|\varepsilon|$ & $\begin{array}{l}\text { Input of speed transmission } \\
\mathrm{r} / \mathrm{min}\end{array}$ & $\begin{array}{l}\text { Input of steering } \\
\mathrm{r} / \mathrm{min}\end{array}$ \\
\hline 1 & The constant radius steering & 600 & 1 & 4.91 & $=1$ & 122.20 & 504.20 \\
2 & The constant radius steering & 1000 & 2 & 1.79 & $=1$ & 558.66 & 840.34 \\
3 & The constant radius steering & 1300 & 3 & 0.89 & $=1$ & 1460.67 & 1092.44 \\
4 & The constant radius steering & 1700 & 4 & 0.54 & $=0.6$ & 3148.15 & 2380.95 \\
5 & The constant radius steering & 500 & $\mathrm{R}$ & -5.89 & $=1$ & -84.89 & 420.17 \\
\hline
\end{tabular}




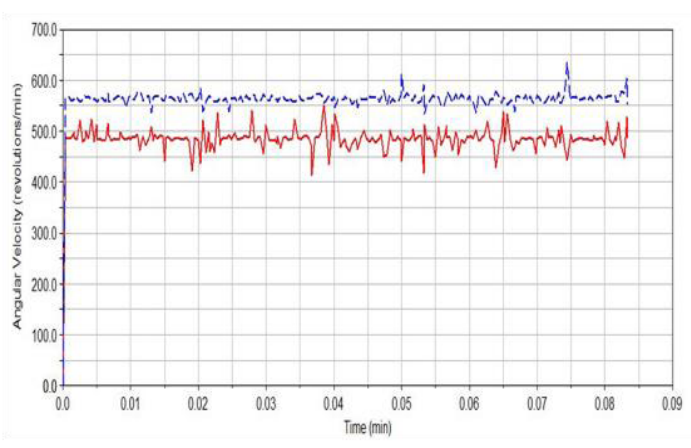

Figure 5. Speed of planet carrier in constant radius steering of gear 2 .

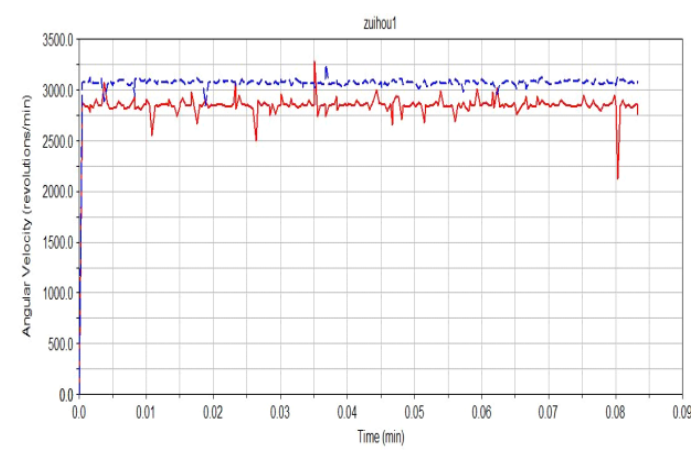

Figure 7. Speed of planet carrier in constant radius steering of gear 4 .

Through the comparison of the graphs, it can be found in the rough count, with steering angle unchanged, the higher gear, the greater the relative steering radius. The curve fluctuations in gear one are relatively obvious. It indicates, in a low speed, the fluctuations of speed are relatively obvious. That means its models were built and assembled inaccurately. Especially the gaps between gears are relatively large, resulting in unstable speed and vehicle vibration. It shows that it should be paid attention to improve the precision in manufacturing and assembly in the actual assembly.

\subsection{The variable radius steering simulation}

The simulation condition is described in Table 2 . Some simulation results are shown in Figures 9-12.

Through the observation of graphs it can be found that, with the increase of steering angle, the speed difference of planet carriers is increasing when gear and engine speed is certain. The sum of two planet carriers' speed is almost unchanged. Without considering ground resistance, the overall turning speed of the vehicle is constant. But in practice, the effect of ground resistance on vehicle steering is great. Therefore, if you want to steer at a constant speed, tracked vehicles should be increase the throttle in the process of actual driving.

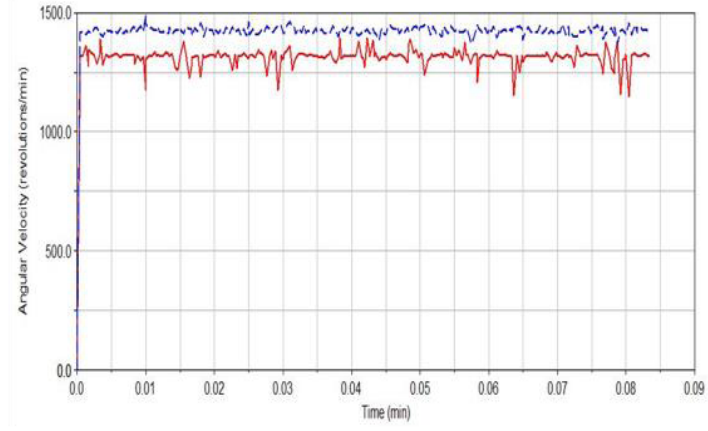

Figure 6. Speed of planet carrier in constant radius steering of gear 3.

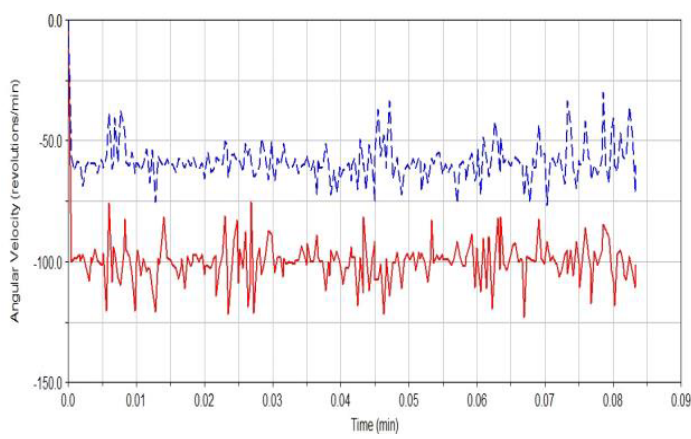

Figure 8. Speed of planet carrier in constant radius steering of reverse gear.

\subsection{Neutral steering simulation}

The simulation condition is described in Table 3 . Some simulation results are shown in Figures 13-19.

When ground resistances are equal, the speed of both sides of the planet carriers is approximately equal and opposite, as shown in figure 13. When the ground resistance of one side is smaller than the other side, the rotating speed of the planet carrier is faster than the other one. Faster side rotates more and more quickly and slower side rotates more and more slowly. The speed of two sides is stabilized until equilibrium is reached, as shown in figure 14 and 15 . When the difference of resistance of both sides increases gradually, the speed of slower side reduces more quickly. When the speed of slower side reduce to zero, the eccentric steering turns to ground braking steering, as shown in figure 16 and 17 . When the ground resistance of one side is much smaller than the other side, vehicles turn to ground braking steering at the beginning, as shown in figure 18 . When $|\varepsilon|$ is variable, the angle of vehicle steering increase evenly along with steering wheel and the resistance of both sides are equal, as shown in figure 19. 


\section{MATEC Web of Conferences}

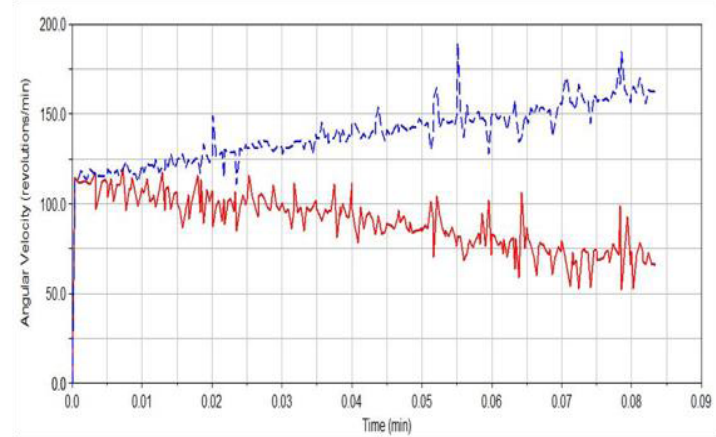

Figure 9. Speed of planet carrier in variable radius steering of gear 1.

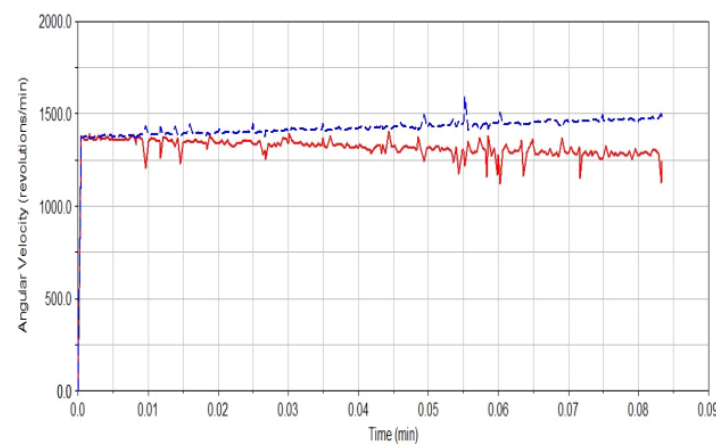

Figure 11. Speed of planet carrier in variable radius steering of gear 3

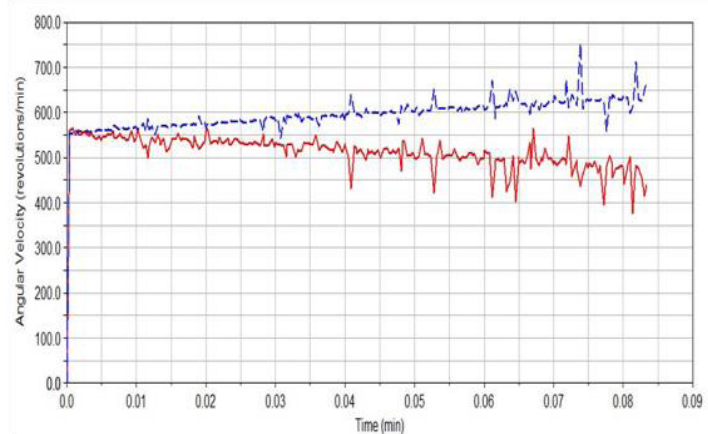

Figure 10. Speed of planet carrier in variable radius steering of gear 2.

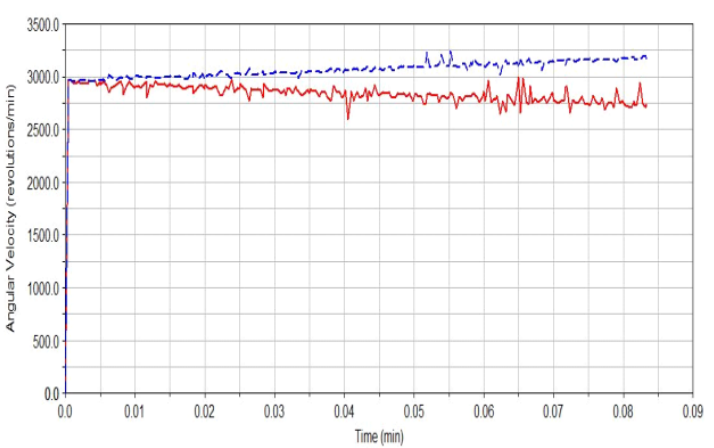

Figure 12. Speed of planet carrier in variable radius steering of gear 4

Table 2. Simulation of variable radius steering

\begin{tabular}{|c|c|c|c|c|c|c|c|}
\hline No. & The simulation condition & The engine speed $\mathrm{r} / \mathrm{min}$ & Gear & $i_{b}$ & $|\varepsilon|$ & $\begin{array}{l}\text { Input of speed transmission } \\
\mathrm{r} / \mathrm{min}\end{array}$ & $\begin{array}{l}\text { Input of steering } \\
\mathrm{r} / \mathrm{min}\end{array}$ \\
\hline 1 & Variable Radius Steering & 600 & 1 & 4.91 & $\leq 1$ & 733.20 & $0 \sim 504.20$ \\
\hline 2 & Variable Radius Steering & 1000 & 2 & 1.79 & $\leq 1$ & 3351.96 & $0 \sim 840.34$ \\
\hline 3 & Variable Radius Steering & 1300 & 3 & 0.89 & $\leq 1$ & 8764.04 & $0 \sim 1092.44$ \\
\hline 4 & Variable Radius Steering & 1700 & 4 & 0.54 & $\leq 0.6$ & 18888.89 & $0 \sim 2380.95$ \\
\hline
\end{tabular}

Table 3. The simulation conditions of neutral steering

\begin{tabular}{|c|c|c|c|c|c|c|}
\hline No. & The simulation condition & $\begin{array}{l}\text { Outside resistance } \\
\mathrm{N} / \mathrm{m}\end{array}$ & $\begin{array}{l}\text { Inside resistance } \\
\mathrm{N} / \mathrm{m}\end{array}$ & $\begin{array}{l}\text { The engine } \\
\text { speed } \mathrm{r} / \mathrm{min}\end{array}$ & $|\varepsilon|$ & $\begin{array}{l}\text { Input speed } \\
\mathrm{r} / \mathrm{min}\end{array}$ \\
\hline 1 & Center steering & 300 & 300 & 600 & $=1$ & 504 \\
\hline 2 & Eccentric steering & 300 & 600 & 600 & $=1$ & 504 \\
\hline 3 & Eccentric steering & 300 & 900 & 600 & $=1$ & 504 \\
\hline 4 & Eccentric steering & 300 & 1500 & 600 & $=1$ & 504 \\
\hline 5 & Eccentric steering & 1500 & 300 & 600 & $=1$ & 504 \\
\hline 6 & The ground braking steering & 300 & 5000 & 600 & $=1$ & 504 \\
\hline 7 & Center steering & 300 & 300 & 600 & $\leq 1$ & $0 \sim 504$ \\
\hline
\end{tabular}


ICETA 2015
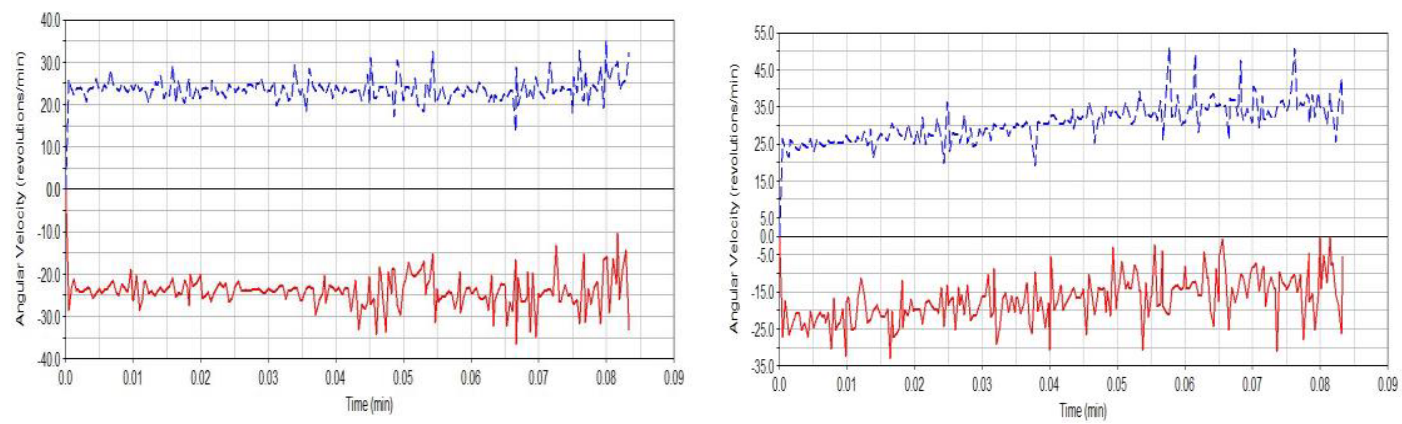

Figure 13. Speed of planet carrier in NO.1 center steering.

Figure 14. Speed of planet carrier in NO.2 center steering.
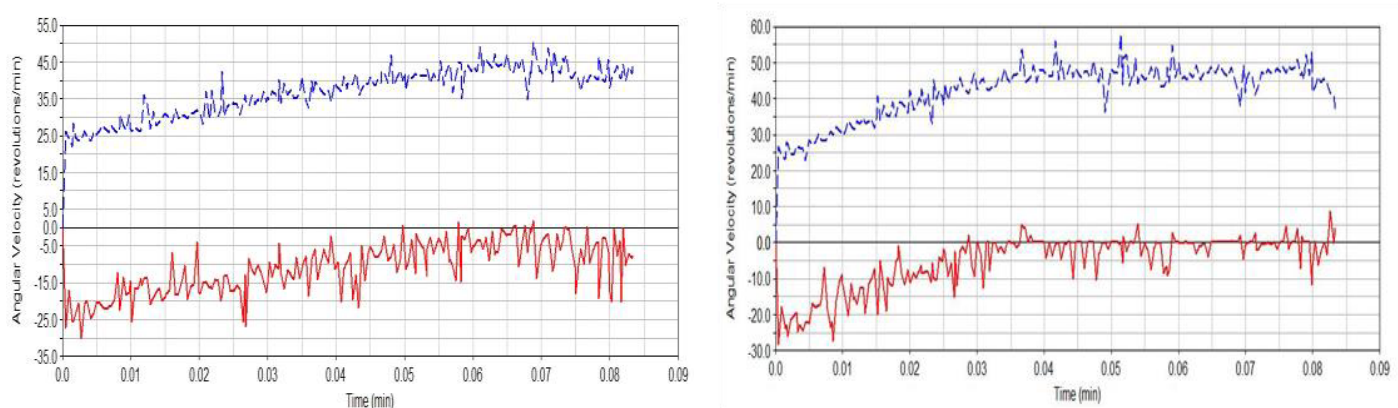

Figure 15. Speed of planet carrier in NO.3 eccentric steering

Figure 16. Speed of planet carrier in NO.4 eccentric steering.

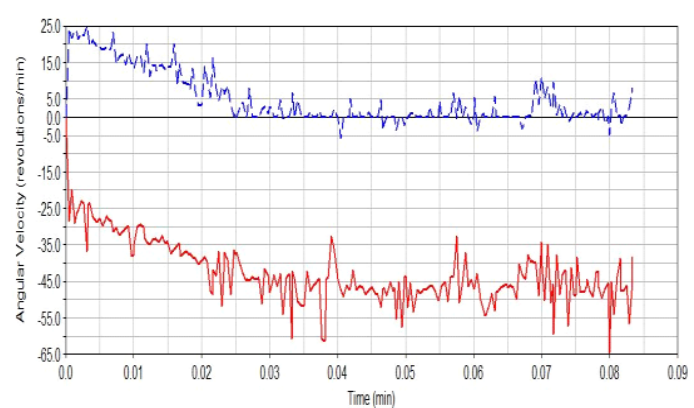

Figure 17. Speed of planet carrier in NO.5 eccentric steering.

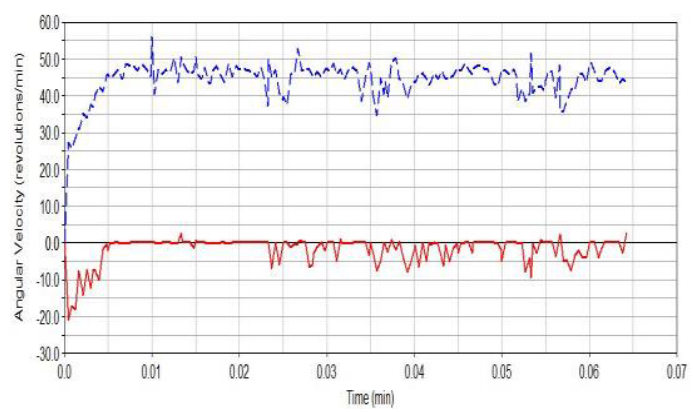

Figure 18. Speed of planet carrier in NO.6 ground braking steering.

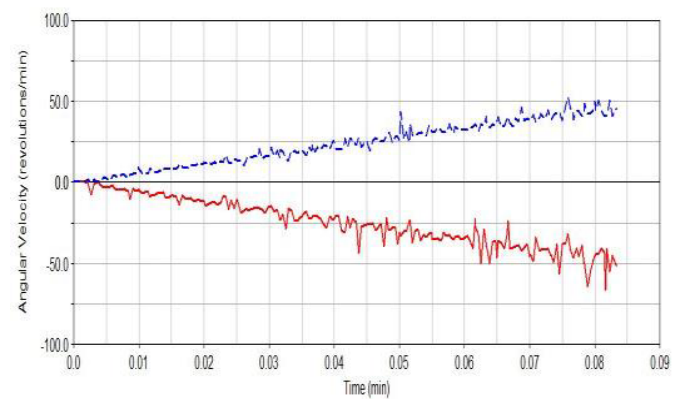

\section{CONCLUSIONS}

The radius of neutral steering depends mainly on the resistance of steering. Because inside and outside vibration factors exist, both sides of vehicle will appear at unstable speed. The curve fluctuations in gear one is relatively obvious. It indicates the gaps between gears are relatively large. So we need to pay attention to improve the precision in manufacturing. Different from wheeled vehicles, in tracked vehicles, you need

Figure 19. Speed of planet carrier in NO.7 variable $|\varepsilon|$ center steering 


\section{MATEC Web of Conferences}

to increase the throttle in order to hold an unchanged speed.

Ground resistances are the main influencing factors to the steering of vehicle. Because of different ground resistances, the steering is divided into center steering, eccentric steering, and ground braking steering and each steering has its own characteristics.

The simulation results verify the reliability of dual-stream transmission system of the unmanned tracked armored vehicle.

\section{REFERENCES}

[1] Sun, Wei. 2006. Structure of Armored Vehicle. Beijing The Publishing House of Ordnance Industry.

[2] Sun, Wei. \& MA, Bing. 2014. Reliability analysis of the suspension device in the refit of a tracked vehicle. $A d$ vanced Materials Research. pp: 945-949.

[3] Okhyun, Kang. 2009. Look-ahead preview control application to the high-mobility tracked vehicle model with trailing arms. Journal of Mechanical Science and Technology.

[4] Sangkyu, Lee. 2008. A multibody-based dynamic simulation method for electrostatic actuators. Nonlinear Dyn.

[5] Van Kasteel, Richard. 2004. Study of a dynamic mathematical model for hydraulic damper. China Railway Science.

[6] Titurus, Branislav. 2012. Modeling and testing of a semiactive hydraulic damper in periodic working regimes. Department of Aerospace Engineering, 00011452. 